\title{
DIALÉTICA E CONTRADIÇÕES DA CONSTRUÇÃO DA IDENTIDADE
} SOCIAL ${ }^{1}$ DIALECTIC AND CONTRADICTIONS OF SOCIAL IDENTITY CONSTRUCTION

\section{RESUMO}

Nesse artigo são discutidos os desafios para a atuação dos psicólogos latino-americanos, do ponto de vista de sua prática e da produção de conhecimento, no sentido de atender uma região do planeta que sofre males endêmicos ao mesmo tempo em que é de interesse estratégico para o capital financeiro internacional e conglomerados comerciais. Apesar de tudo, sobrevivem formas culturais tradicionais, construções culturais que estão em contato direto ou indireto com as formas de cultura dominadas pelo mercado mundial. Tal dominação produz efeitos importantes nas expressões subjetivas sociais, as dimensões subjetivas da realidade, reconfigurando as formas tradicionais de manifestação da cultura e exigindo estratégias de resistência no enfrentamento das contradições entre cultura globalizada e cultura tradicional. Como forma de entendermos melhor o funcionamento dessas dimensões, discutimos a relação entre o território, lugar da expressão do sujeito, e a construção de registros globalizados que exigem ressignificação da cultura.

Palavras-chave: identidade social; dimensões subjetivas da realidade; globalização; território.

\begin{abstract}
In this article we aim to discuss the challenges imposed in the work of Latin- American psychologists, from the production of knowledge to the practical point of view, which would attend a region of the planet that suffers from endemic problems and at the same time, is of great importance for international financial capital, for big commercial conglomerates. After all, traditional cultural forms survive, cultural constructions that are in constant direct or indirect contact with the cultural ways dominated by the global market. This domination produces important effects on subjective social expressions, the subjective dimensions of reality, reconfiguring the traditional forms of manifestation of culture and demanding strategies of resistance in facing the contradictions between traditional culture and globalized culture. As a way to better understand the functioning of the subjective dimensions, we will discuss the relationship between territory, location of expression of the subject, and the construction of records that require reinterpretation of globalized culture.
\end{abstract}

Keywords: social identity; subjectivies dimensions of reality; globalization; territory.

A partir da década de 80 , o termo globalização passou a ser obrigatório no vocabulário dos que discutem os caminhos da economia e da política mundial. Com o declínio do comunismo, já antes da queda do muro de Berlim e do fim da União das Repúblicas Socialistas Soviéticas, passamos a ter uma nova configuração geopolítica no planeta, com o indiscutível domínio dos Estados Unidos da América e a nova hegemonia capitalista. Essa hegemonia é efetivada através da interferência dos organismos internacionais como Fundo Monetário Internacional (FMI), Banco Mundial, Banco Interamericano de Desenvolvimento (BID) e outros mecanismos de intervenção, com forte influência americana, nas economias locais dos países pobres, garantindo a presença de um modelo universal de manejo da economia e da gestão pública e privada. De acordo com Wallerstein (2003a), toda essa política, também conhecida como Consenso de Washington, veio substituir o período de política desenvolvimentista, dominante no período anterior. No seu lugar, é proclamada a política de globalização, que preconizava o triunfo do livre mercado, a redução radical do papel econômico do Estado e, sobretudo, a eliminação de todas as barreiras estatais aos movimentos transnacionais de bens e capitais.

As bases para a mudança de rumo da economia mundial capitalista foram dadas a partir do ciclo de crises econômicas sofridas pelos principais centros da 
economia mundial a partir do início da década de 80 , e tal crise afeta tanto os países que representam o centro do capitalismo como os periféricos e a economia socialista. A reordenação econômica, buscando novo ciclo de crescimento, não está isolada de todos os outros fatores, como os políticos, sociais, psicológicos, e vimos, a partir de então, uma série interminável de consequências direta ou indiretamente ligadas à alteração da política desenvolvimentista e à aplicação da política da globalização do mercado capitalista.

Hoje, passados vinte anos de implantação da nova política econômica mundial, cabe realizarmos a análise do que ela induz como novas formas de sociabilidade e subjetividade. Vivemos hoje o que alguns autores chamam de nova ordem social. É o caso de Hardt e Negri (2001), e é o caso também dos ingleses Hutton e Giddens (2004). Os dois primeiros se notabilizaram recentemente pela publicação Império, na qual defendem que a definição do imperialismo, como se apresentava durante o período de colonização que durou até o início do século XX, não faz sentido nos dias de hoje e que não haverá mais a possibilidade de uma potência mundial, de um estado-nação, que tenha domínio territorial sobre outros. Sua hipótese sobre a nova ordem mundial é que "a soberania tomou nova forma, composta de uma série de organismos nacionais e supranacionais, unidos por uma lógica ou regra única. Esta nova forma global de economia é o que chamamos de Império" (Hardt \& Negri, 2001, p. 12). Entendem os autores que o termo Império é completamente diverso do termo imperialismo. Para eles, o imperialismo era a extensão da soberania dos estados-nação europeus além de suas fronteiras, enquanto o império não estabelece um centro territorial de poder e não se baseia em fronteiras ou barreiras fixas. Ainda nas palavras dos autores, é um aparelho de descentralização e desterritorialização do geral que incorpora gradualmente o mundo inteiro dentro de suas fronteiras abertas e em expansão. Nesse sentido, os autores apontam corretamente a maneira como se expressa a hegemonia americana e sua forma de espraiamento por todas as economias do planeta. ${ }^{2}$

Para Giddens, no presente momento o termo globalização é encontrado por toda parte, e a sua disseminação mundial é a prova das próprias mudanças que ele descreve. De acordo com o autor, algo muito novo está acontecendo no mundo, e não se trata de um simples conjunto de mudanças, mas que várias tendências estão sobrepostas, e aponta quatro delas: a primeira é a revolução mundial das comunicações, iniciada na década de 60 com o primeiro satélite colocado em órbita e com a intensificação das comunicações globais a partir de então chegando até a internet. O segundo diz respeito ao que ele chama de "economia sem peso" ou economia do conhecimento, que funciona com prin- cípios diferentes da economia industrial e tem como vanguarda o mercado financeiro. Em terceiro lugar, a queda do comunismo soviético que, para o autor, estava sustentado na economia industrial e não conseguiu competir na nova economia eletrônica global. Por fim, a globalização refere-se a mudanças profundas que acontecem na vida cotidiana, sendo uma das maiores a crescente igualdade entre homens e mulheres. Mudanças que afetam a família e a vida emocional não somente no ocidente, mas, em maior ou menor grau, em todas as sociedades do planeta. Finalmente, diz que, quando se juntam esses quatro fatores, o nível de transformação global não fica longe do espetacular (Hutton \& Giddens, 2004, pp. 13-14).

Já Hutton, se contrapondo a Giddens, aponta que de fato há alguma coisa revolucionária acontecendo, especialmente com a tecnologia, mas aponta que a globalização é uma ideia poderosa por causa da sensação de não se ter como escapar dela, e nessa história está incluído o declínio da soberania nacional. Combate a concepção de economia sem peso, da economia do conhecimento de Giddens, salientando que a expansão dos serviços ligados à saúde e à assistência à terceira idade está ligada a uma sociedade que está enriquecendo e se tornando mais velha e nada tem a ver com a economia de conhecimento e que todos esses setores utilizam a tecnologia de informação, mas não foi a revolução da tecnologia da informação que criou seu crescimento. Também acha um erro grave subestimar a importância do crescimento do crime, da corrupção e da evasão fiscal como característica da globalização (Hutton \& Giddens, 2004, p. 17).

$\mathrm{O}$ debate entre esses dois autores, que veem a globalização como mal necessário, é bastante interessante e mostra os caminhos que a social-democracia inglesa está escolhendo no presente momento. Giddens, o formulador da terceira via, vê como única saída fazer avançar os caminhos atuais do capitalismo, acreditando numa saída no final do túnel. Chega mesmo a apontar que Fukuyama (1992), muito conhecido pela publicação de $O$ fim da história e o último homem, que pregava a eternização do capitalismo a partir da queda do muro, poderia ter alguma razão. Já Hutton acredita na humanização do capitalismo, naquilo que ele define como "capitalismo das partes interessadas", o que significa dizer um capitalismo em que a negociação entre os acionistas, os consumidores, os sindicalistas etc., mediada pelo Estado, poderá garantir o controle social do avanço capitalista, e dá como exemplo a política da social-democracia alemã. ${ }^{3}$

Vimos, até agora, autores importantes que apontam ser a globalização consequência do próprio avanço do capitalismo, e uns veem esse processo de forma otimista, como é o caso de Giddens e de Hutton, e outros de forma 
crítica, como Hardt e Negri, mas todos eles apontam a globalização como processo histórico novo e inevitável.

Wallerstein se contrapõe a esses autores com a tese que diz ser a globalização um processo antigo e de cunho expansionista. É a própria busca de mercado, quando esse se esgota nos principais centros capitalistas, que move a máquina econômica. $\mathrm{O}$ seu argumento está exposto em recente entrevista a um jornal brasileiro:

Em primeiro lugar, eu acho que o termo 'globalização' é em grande parte um slogan e uma mistificação, não uma realidade nova. Estamos falando é da liberdade de movimento dos fatores de produção versus protecionismo. Isso tem sido uma questão por 500 anos. Países foram para um lado e para outro na questão, porque há vantagens em ambos, para todos. No momento, os EUA têm liderado um grande esforço para derrubar barreiras, especialmente de fluxos de capital. Os fluxos financeiros sempre foram os mais controlados de todos. Os EUA tiveram um certo nível de sucesso nos últimos dez anos, conseguindo com que países fizessem coisas para as quais eles ainda não estavam preparados. Por um lado, essa iniciativa começou com muito êxito. Quando você proclama que não há alternativas ao modelo neoliberal, o que está querendo dizer é que não deveria haver outras alternativas, mas, obviamente, elas existem ... Então a combinação da discussão, simbolicamente, do FMI - Banco Mundial e a crescente resistência de alguns países definitivamente diminuíram o grau de abertura. Mas isso não é nada de novo, acelera e regride o tempo todo, e certamente o livre comércio não é uma panacéia. Quer dizer, a idéia de que você deve competir não tem nada de novo - o que é o capitalismo senão a teoria de que você tem de ser competitivo no mercado mundial? (Wallerstein, 1999, pp. 5-9)

Mais recentemente, em artigo publicado pela $\underline{\mathrm{New}}$ Left Review, Wallerstein (2003b) chega a apontar para uma crescente desarticulação da ordem mundial. Diz ele que, neste momento, caminhamos para um futuro imediato incerto e, em momentos de anarquia sistêmica, como o atual, qualquer coisa pode suceder, e essa coisa diz respeito ao fato de que, para ele, é evidente o declínio da hegemonia americana, sem que se vislumbre o que ocupará o vácuo do espaço deixado por eles. ${ }^{4}$

Mesmo raciocínio segue o historiador Perry Anderson (2002). Apesar de não acatar a concepção de anarquia sistêmica de Wallerstein, aponta que a hegemonia americana, no sentido gramsciano do termo, é insustentável.

Optamos por trabalhar a opinião de autores reconhecidos no cenário mundial e identificar três correntes sobre os caminhos do capitalismo atualmente, da globalização e do futuro que nos espera. A saber, uma posição da social-democracia europeia, a outra do campo pós-moderno e outra da esquerda tradicional. Omitimos, deliberadamente, a posição do campo neoliberal ou da ortodoxia capitalista. Não foram consultados economistas; nossos autores são sociólogos, filósofos, linguistas, historiadores. Notem que, apesar da diversidade, não há psicólogos entre eles, e mesmo no campo da psicologia social não é fácil encontrar interlocutores sobre esse assunto. Exceção feita ao campo da economia conservadora, que ofereceu um Nobel a um psicólogo, Daniel Kahneman (2000), que editou, entre outros, Choice, Values and Frames, no qual escreve um artigo sobre o critério de escolha e julgamento utilizado pelas pessoas no seu dia-a-dia. Enfim, a despeito do alto valor preditivo de suas categorias, ele se encontra no campo da microeconomia, e não tem a possibilidade de enxergar o fenômeno econômico como os demais autores citados nesta exposição.

O fato é que nos últimos anos estivemos influenciados pelo fenômeno da globalização, ora procurando entendê-lo, como se disso dependesse nosso futuro, ora procurando negá-lo, considerando que o problema seria de outra ordem. Mesmo um analista potente como Wallerstein, ao apontar que o fenômeno não é novo, toma o fenômeno como dado. É possível deduzir que a dialética produzida pelo terceiro mundo no confronto com o primeiro (a classificação parece completamente fora de propósito, mas é a que temos) é completamente desconsiderada quando se fala em globalização. $\mathrm{O}$ confronto entre o território e o sistema global é sempre visto do ponto de vista deste último. Prevalece sempre o ponto de vista da mundialização, o ponto de vista da dinâmica mundial do capital em detrimento das ações locais. Ações locais que podem ou não estar conectadas com o padrão global.

Nesse sentido, impressiona muito a condição em que se encontra a América Latina. Todos sabem que nossa colonização ibérica - espanhola e portuguesa - construiu uma identidade latino-americana, que se expressa em nossa base religiosa, em nossa organização peculiar, em nossa linguagem, em nossos costumes. A miscigenação do colonizador, ora com os habitantes originários da terra, ora com povos africanos para cá trazidos à força, ora com as duas etnias, em outros casos acrescida da imigração italiana, japonesa, chinesa, alemã, produz essa feição latino-americana. Ao mesmo tempo, somos diferentes e somos às vezes diferentes até mesmo no microcosmo, diferentes em nossos próprios países. ${ }^{5}$

Numa região das mais bonitas e instigantes do planeta, o deserto de Atacama, no norte do Chile, há uma pequena vila (um pueblito) denominada Caspana. O que impressiona nesse lugar é que a arquitetura segue o padrão Inca, os primeiros imperialistas da região, que ali chegaram ao final do século XV, pouco antes dos espanhóis. Provavelmente, pela aridez do terreno e pela falta de atrativos que pudessem interessar à Espanha, essa pequena vila foi deixada em paz. Diferentemente 
das vilas próximas que seguem o padrão arquitetônico espanhol, Caspana apresenta uma característica muito peculiar, e podem-se observar exemplos da construção típica dessa região.

Figuras 1 e 2 - exemplos de construções típicas de Caspana*
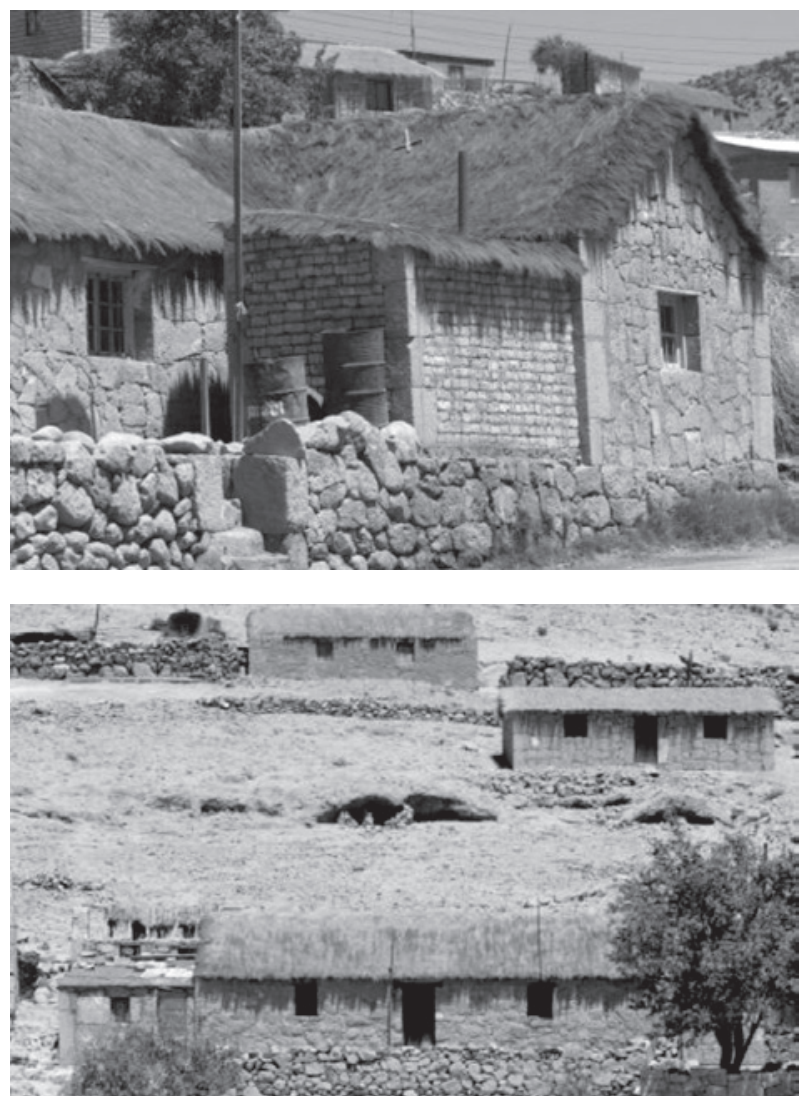

Fonte: http://inema.com.br/eventos/02072/fotos/15CaspanaN/0B2F0688. htm

Muito bem, as tradições foram preservadas até os dias de hoje. Mas estão eles completamente isolados do mundo de hoje? Evidentemente, não! Têm acesso à educação no padrão chileno, acesso a todo tipo de comunicação moderna e, ao mesmo tempo, boa parte da população vive da economia de subsistência. Também recebem, todos os dias, visitantes de todo o planeta, que vão até lá para conhecer as belezas do deserto nas altitudes dos Andes.

De acordo com Castro e Martinez (1996), há uma organização muito peculiar da economia local, de base comunitária, que afeta a organização política dessa comunidade cujas decisões são sempre tomadas através de reuniões comunais. Há também uma expressão religiosa sincrética que associa a visão indígena e a católica. A forma de organização comunitária é forte e demonstra como a organização pré-colombina permaneceu quase intacta até os dias de hoje.

Dos espanhóis, herdaram a língua, alguns costumes e a base da religião católica. Há uma igreja católica na vila, mas, apesar de sua importância para o local, não está numa Plaza de Armas e não tem a arquitetura típica do colonial espanhol. Pelo contrário, segue o padrão arquitetônico das construções pré-colombianas. É preciso considerar, evidentemente, a imposição da religião da forma com foi realizada pelos espanhóis durante a colonização. Os efeitos repressivos da colonização espanhola sobre a cultura autóctone encontraram eco na visão autoritária da ditadura chilena recente, encabeçada pelo general Pinochet, que proibiu qualquer outra língua no país (as várias línguas indígenas) que não a espanhola ${ }^{6}$.

No Brasil, no Planalto Central, relativamente próximo da capital federal, Brasília, vive um povo conhecido como Kalunga. São descendentes de ex-escravos que fugiram das fazendas da região no final século XVIII ou foram deixados para trás depois do esgotamento do ouro na região e formaram um quilombola ${ }^{7}$.

Uma vila que, pelas circunstâncias, se localizava em local ermo e de difícil acesso, Kalunga é um desses quilombos que só muito recentemente foram descobertos.

Figura 3 - vista de construção típica do quilombola Kalunga.

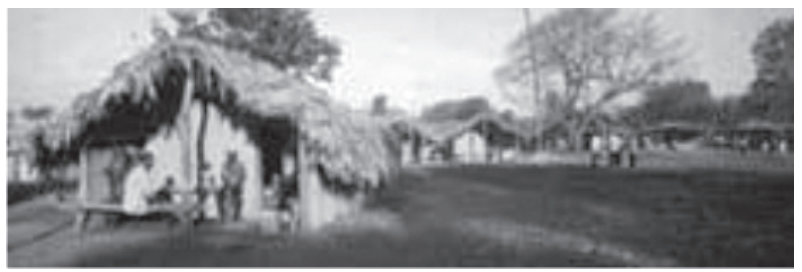

Gerações e gerações ali viveram sem contato com o que ocorreu no Brasil nos últimos 200 anos. O contato era feito por raros viajantes que se aventuravam a atravessar uma região inóspita e pelos próprios habitantes Kalungas, que buscavam o necessário para o grupo nas cidades mais próximas. Ainda hoje, não há como chegar às regiões mais afastadas, habitada pelos Kalungas, através de qualquer outro transporte que não seja o animal, fluvial ou a pé. Atualmente, o poder público chegou até esse quilombo, e há programa básico de saúde e educação; entretanto, o grupo mantém suas tradições e costumes. Recentemente o poder público reconheceu o quilombo e garantiu a posse de terra a essa comunidade. Nas observações etnográficas realizadas, Silva (1999) ressalta o aspecto cultural muito peculiar, dado o isolamento, mas, ao mesmo tempo, a construção de maneiras informais de comunicação com o entorno, que permitem a atualização com o que está ocorrendo no mundo. Chama muita atenção o fato de toda tradição religiosa ser de fundo católica, com pouca presença das religiões africanas praticadas no Brasil. Entretanto, o culto católico celebrado pelos 
próprios habitantes (batizados, casamentos, rezas) é realizado em latim. Como o latim foi substituído pelo português na Igreja Católica brasileira há mais de 30 anos (a partir do Concílio Vaticano II), e como não há registro na memória da população de outras formas de culto $^{8}$, tudo indica que o catolicismo está presente entre os Kalungas há muito tempo. Até muito pouco tempo não havia eletricidade na região, não havia nenhuma forma de comunicação moderna, os Kalungas não eram alfabetizados e a única via de informação do que ocorre no mundo era a visita às cidades próximas.

Entretanto, Silva identifica que as "novidades" são rapidamente divulgadas pela forma oral. ${ }^{9}$ A propriedade da terra é coletiva, e não há tradição de acúmulo. Toda economia é de subsistência, e o pouco que se produz com trocas ou comércio (quase não circula moeda) é destinado à compra de utensílios nas cidades próximas. As visitas a essas cidades são frequentes, e a comunidade tem uma caminhonete para esse fim.

Caspana, no norte do Chile, e o quilombo Kalunga, no centro-oeste brasileiro, são dois casos de construção de sociabilidade bastante singulares. Há evidentes contornos de cultura tradicional, mantida por gerações e gerações, e a atualização e acompanhamento dos elementos centrais da modernidade.

A tensão entre o tradicional e o moderno da maneira como aparece entre os povos mencionados se repete ao infinito, e essas formas de constituição de territórios ocorrem mesmo em uma megalópole como a Cidade do México ou a cidade de São Paulo.

Para entendermos a dimensão dessa noção de território, que acabamos de mencionar, será preciso entendê-la como uma nova maneira das populações definirem seus territórios. Considerem que mesmo os Kalungas, isolados no Centro-Oeste brasileiro, não podem mais garantir a não contaminação de sua cultura tradicional. São raras as populações no planeta que ainda não foram contatadas por outros grupos humanos, e as poucas que existem vivem na floresta amazônica. O contato com a chamada civilização ocidental - esse termo também já não faz mais sentido - implica a aquisição do repertório construído pela sociedade industrial, e a troca de repertórios entre as culturas não tem sido vantajosa para as chamadas culturas tradicionais. A cultura da sociedade industrial, fato sobejamente conhecido, também é transformada em um negócio: negócio de massa! E, como tal, segue o padrão do objeto de consumo da sociedade industrial, ou sociedade do conhecimento, conforme a concepção de Giddens, já mencionada.

Esse processo segue o padrão da globalização e se espalha, se imiscui, conquista mercado, rompe territórios; interessa-lhe sempre a economia de escala: seja o aparelho de DVD, como exemplo de equipamento industrializado, seja o filme feito em Hollywood, seja a novela mexicana da Televisa ou a brasileira da Rede Globo, como produto comercial da indústria de entretenimento.

Mesmo assim, as comunidades persistem, se remodelam, reconstroem os elementos dessa cultura de massa a partir de suas experiências e de suas tradições. Reinventam a cada momento suas próprias tradições, dando nova dimensão ao termo tradicional.

De acordo com Milton Santos (2002):

O território são formas, mas o território usado são objetos e ações, sinônimo de espaço humano, espaço habitado. Mesmo a análise da fluidez posta ao serviço da competitividade, que hoje rege as relações econômicas, passa por aí. De um lado temos a fluidez virtual, oferecida por objetos criados para facilitar essa fluidez e que são, cada vez mais, objetos técnicos. Mas os objetos não nos dão senão uma fluidez virtual, porque a real vem das ações humanas, que são cada vez mais ações informadas, ações normatizadas. (p. 16)

\section{E continua:}

As redes constituem uma realidade nova que, de alguma maneira justifica a expressão verticalidade. Mas além das redes, antes das redes, apesar das redes, depois das redes, com as redes, há o espaço, porque as redes constituem apenas uma parte do espaço e o espaço de alguns. O território, hoje, pode ser formado de lugares contíguos e de lugares em rede. São, todavia, os mesmos lugares, os mesmos pontos, mas contendo simultaneamente funcionalizações diferentes, quiçá divergentes ou opostas. (p.16)

Além de Santos, Néstor García Canclini (2003), que chama de cultura híbrida a forma de coexistência de formas tradicionais de cultura e de formas globalizadas, chama atenção para os aspectos regionais e globais da cultura. Discutindo a quem servem os ritos, o autor questiona a hipótese central do tradicionalismo para a qual, para haver identidade cultural, há que haver a construção de um patrimônio, constituído através de dois movimentos: ocupação de território e constituição de acervo. Assim, adquirir identidade significa pertencer a um país, a uma cidade ou a um bairro, uma entidade em que tudo é compartilhado pelos moradores, o que os torna idênticos (Garcia-Canclini, 2003, p. 117). Ocorre que já não é possível falar em antagonismos como popular e erudito, folclórico e artístico, moderno e tradicional, nos tempos atuais. Os territórios não estão mais isolados, e a comunicação é inevitável. Então como tratar a questão da identidade cultural ou identidade social nos dias de hoje?

Para Giddens (2002), a identidade social está intrinsecamente ligada aos padrões impostos pela modernidade, e nesses destaca a reorganização do tempo e do espaço, os mecanismos de desencaixe e a reflexividade da modernidade, que, segundo o autor, 
supõem propriedades universalizantes que explicam a natureza fulgurante e expansionista da vida social moderna em seus encontros com práticas tradicionalmente estabelecidas. A globalização da atividade social que a modernidade ajudou a produzir é, de certa maneira, um processo de desenvolvimento de laços genuinamente mundiais - como aqueles envolvidos no sistema global de estados-nações ou na divisão internacional do trabalho. (Giddens, 2002, p. 27).

No caso dos Kalungas, Silva (1999) relata a maneira rápida como a medicina popular foi abandonada com a chegada dos medicamentos industrializados, e exemplifica com a fala de uma das moradoras do quilombo Kalunga:

Depois que começaram a ir no doutor [na cidade] ninguém confia mais nos remédios daqui. Ninguém sabe mais como cortar raiz de pau. Antigamente assim, quando menino tava doente eu ia pra roça atrás de planta assim e fazia aquele mexido com planta assim e ficava todo mundo bom. Hoje dá até medo de dar chá pros meninos. (Silva, 1999, p. 78)

A tradição da medicina popular que estabelece laços de sociabilidade, que valoriza o saber e a memória popular é substituída rapidamente, e a comunidade se vê inserida no circuito mundial da indústria química. A crença secular é substituída pela crença na tecnologia. Giddens (2002, p. 27) aponta ainda que o distanciamento entre tempo e espaço é a melhor expressão do conceito de globalização, e que ela diz respeito à intersecção entre presença e ausência, ao entrelaçamento de eventos e relações sociais "à distância" com contextualidades locais.

Entretanto, a tese de Giddens não considera a permanência do território e a manutenção das bases territoriais na constituição da identidade. Se a globalização é elemento importante na constituição e transformação da subjetividade, elementos que estruturam o território também o são. No citado caso dos Kalungas, Silva relata um evento conflitante e que tem como centro a noção de propriedade daquela comunidade ${ }^{10}$. Alguns jovens levam para casa um porco retirado do terreno de um vizinho, e isso provoca uma discussão sobre a propriedade do animal. Adultos da família dos jovens dizem que é errado retirar o animal daquele terreno, e os jovens argumentam que um animal não pertence aos terrenos e que, se fosse uma paca, o fato não estaria sendo questionado. Nesse momento interfere o familiar mais velho, que diz ser norma o respeito à propriedade do animal criado, que é diferente da norma do animal selvagem e que, no primeiro caso, deve ser respeitada a noção de propriedade de quem criou o animal.

Está em questão o uso coletivo e o uso privado da propriedade e, note-se, não é o vizinho que reclama o uso da norma, mas uma discussão de jovens e adultos de uma mesma família, que, em última instância, estão dialogando sobre o entendimento das regras jurídicas da comunidade. O processo de socialização ocorre através da tradição oral que rege essa comunidade, não pelo fato que produziu o diálogo, mas pela forma do registro da memória coletiva da regra.

É possível que, com a inevitável integração da comunidade ao padrão de vida tipicamente brasileiro e as suas formas de socialização (suas formas identitárias) e pela dinâmica socioeconômica do país, muita coisa se altere na comunidade Kalunga e, a despeito de prática preservacionista em curso, em longo prazo não se aplique mais o termo "comunidade" a essa população. Entretanto, como ocorre em Caspana, será possível preservar características de interesse da própria população, por ela mantidas, de formas de sociabilidade que conviverão com outras, constituídas pelo processo de globalização a que se refere Giddens, provocando o que García Canclini chama de cultura híbrida.

Podemos afirmar que a cultura híbrida é fenômeno decorrente daquilo que Milton Santos chama de dialética da globalização e do território, e me parece que essa definição serve para discutirmos o campo da psicologia social.

Cabe mencionar, antes de iniciarmos essa discussão, que, em geral, a psicologia tem trabalhado com o paradigma positivista de construções teóricas universais, o que significa que acredita numa certa noção de verdade. $\mathrm{O}$ fato é que nossas teorias buscam explicações gerais - o psiquismo, para a psicanálise, é universal, e, se acompanharmos o debate entre Didieu Anzieu e Jean-Pierre Vernant \& Vidal-Naquet (1977), podemos afirmar que é também atemporal: o psiquismo é visto como fenômeno a-histórico. Tomamos a psicanálise como exemplo, mas não é essa teoria a única a padecer desse mal. ${ }^{11}$ Se falarmos da teoria das atitudes, da dissonância cognitiva ou mesmo das representações sociais, que buscam abordagem mais crítica, poderemos assim classificá-las. Um bom exemplo de nossas preocupações epistemológicas está na discussão sobre o paradigma da psicologia a partir da visão de Thomas Kuhn (1978). Ao insistirmos na busca de um paradigma para a Psicologia, não estaremos fazendo uma confissão de que buscamos uma verdade absoluta do psiquismo?

Não atentamos que o psiquismo é social e historicamente construído e que a subjetividade é um fenômeno social, fruto da forma como a humanidade desenvolve seu processo produtivo: de produção de coisas e produção de conhecimento. Produzir coisas e conhecimento é parte de um mesmo processo dialético historicamente determinado, o que significa dizer que os campos objetivo e subjetivo estão indelevelmente interrelacionados e são indivisíveis, que a produção subjetiva de um determinado período corresponde aos 
modos de produção das coisas e do conhecimento. Exatamente por esse motivo preferimos denominar o campo subjetivo produzido socialmente de dimensão subjetiva da realidade, na medida em que essa expressa o aspecto subjetivo que decorre e ao mesmo tempo influencia a outra dimensão, a dimensão objetiva da realidade (Furtado, 2008).

Ocorre que, com o advento deste mundo na forma de rede, como menciona Milton Santos, o local e o universal estão em cheque. Não é possível a construção de conhecimentos locais legítimos, não há possibilidade de isolamento no mundo de hoje. Ao mesmo tempo, e também porque o território é real e ele próprio a condição real de vida das pessoas "lá", no território ocorre uma determinada relação que é universal e particular. Única e genérica, como único e genérico é o próprio ser humano. Nossas teorias devem responder exatamente a essa condição: a condição do ser humano genérico, como está apontada na ontologia de Lukács (1981), e à condição concreta e particular de seu desenvolvimento em seu território.

Não faz mais sentido a discussão sobre Estado nacional, da maneira como fizeram autores como Silvio Romero e Euclides da Cunha. Naquele momento, esses autores buscavam compreender, cada um a seu modo, o que seria a identidade social do brasileiro. Duas vertentes animavam os autores da virada do século XX: a vertente das teorias racistas, que identificavam o caráter dos indivíduos conforme sua raça, e as lutas pela unificação dos países europeus que geraram os estados-nação. A primeira vertente chega ao Brasil trazida por Tobias Barreto, professor da Faculdade de Direito de Recife a partir de 1882, e influenciou fortemente o pensamento de sua época, particularmente Silvio Romero. Barreto, de tendência francamente germanófila, defendeu o naturalismo e foi o primeiro a introduzir a discussão sobre o caráter em nosso meio. Esse período foi o da própria constituição do Estado, com a instauração da República, e tais teorias contribuíam para justificar a estruturação das classes sociais a partir de um novo ideário liberal e, ao mesmo tempo, garantir controle de relações sociais e privilégios para o campo oligárquico. Ou seja, agora todos são livres para o trabalho, e alguns para exercer o poder. Teorias que garantiam que bases genéticas das raças produziam caráter de mando, de inteligência, de civilidade, também garantiam relações de mando e subalternidade, justificadas cientificamente.

Estamos aqui apontando a forma, do ponto de vista dos setores dominantes da sociedade, como se procedeu à identificação do que era ser um brasileiro e, para tanto, se buscou um modelo abstrato reproduzido pela literatura, pelas Leis, pelo estabelecimento de normas e costumes, pela divulgação dos critérios através das instituições vigentes, e a Igreja Católica foi uma das mais importantes nesse processo. O território, do ponto de vista simbólico como produtor de dimensões subjetivas, contava pouco porque estava isolado e não concorria com o centro de produção de subjetividade social.

Os Kalungas já existiam, mas não eram conhecidos pela metrópole, dado o seu isolamento. Quando manifestações advindas de um determinado território, de cunho contestatório, se manifestavam, eram imediatamente reprimidas. Foi o caso de Canudos (1896-1987) e do Contestado (1912-1916), que se insurgiram contra o poder da nascente República por motivos diferentes, mas de caráter regional. No caso de Canudos, a compreensão de que a laicização do Estado corromperia a fé cristã e, no caso do Contestado, a desatenção aos camponeses e trabalhadores durante a construção da estrada de ferro entre o Paraná e Santa Catarina. Mas, em ambos os casos, foram tratados como inimigos da República e como exemplo de que qualquer tentativa restauracionista seria combatida pelo Estado como inimigos da sua inevitável modernização. Aqui já vemos claramente o signo da modernidade sendo utilizado como referência para a nova subjetividade social e como elemento de constituição de nossa nova identidade.

Tudo muda, do ponto de vista da construção de uma identidade nacional, com a Revolução de 30. Entram em cena, agora como agentes do processo de modernização, as classes populares, e a luta de classes ocupa a cena central. Esse episódio é marco da construção de uma nova nacionalidade, que passa a ser discutida de forma intensa por autores como Gilberto Freyre, Caio Prado Jr., Sérgio Buarque de Holanda e, logo em seguida, Antônio Candido e Florestan Fernandes, entre outros. Ao mesmo tempo em que é definida claramente a noção da identidade do brasileiro, identifica-se a baixa autoestima de nosso povo. Povo que ganha importância no cenário nacional a partir do advento de políticas populistas e nacionalistas que reforçam o campo da identidade nacional.

A terceira fase é a que prepara o Brasil para enfrentar o período monopolista, que exige transnacionalização do capital e multinacionalização da produção industrial nos países periféricos. O Brasil é estratégico para essa política na América Latina e, do ponto de vista geopolítico, a interferência americana e as condições locais nos levaram aos longos anos de ditadura militar, que duraram de 1964 a 1985. Nesse período há a desnacionalização da economia, severo controle político e forte apelo publicitário pela união nacional em torno dos ideais políticos dos detentores do poder, que implicava certo ufanismo nacionalista. Essa fase prepara o período do neoliberalismo e da franca desnacionalização do capital, além dos efeitos do que se convencionou chamar de terceira revolução industrial, que discutimos no início deste artigo. Assim, estamos 
neste momento preparando as bases da construção de novas dimensões subjetivas da realidade e de uma nova definição de nossa identidade.

Ciampa (1999) $)^{12}$ menciona a identidade como metamorfose e emancipação:

Assim, por exemplo, em relação à questão de um paradigma latino-americano, diferente de um norte americano ou europeu (v. Montero acima), parece no fundo tratar-se de discutir as formas que a metamorfose humana assume em diferentes contextos culturais e a partir de diferentes leituras. Ontem, na mesa sobre os 500 anos do Brasil, foi possível verificar (em termos esquemáticos) que a identidade coletiva do brasileiro se constituiu como "colonizado", transformando-se em "endividado" após a independência, tendo se modificado, ainda como "endividado", com a globalização. Só para mencionar uma outra leitura, há um estudo que fala da acusação que se faz ao imperialismo inglês, a que Margareth Tatcher teria respondido que de fato o que aconteceu é que a colonização inglesa de fato “civilizou” o mundo. Ou seja, na perspectiva européia, nós - latino americanos - nos metamorfoseamos em “civilizados"! Daí a controvérsia "psicologia da libertação" e "abordagem assistencialista". O que quero chamar a atenção é que sempre estamos falando de metamorfose para definir uma identidade ("colonizado", "civilizado", etc.). (p. 2)

Para Ciampa, somente é possível emancipação e transformação efetiva de um povo quando ele assume os destinos de sua história. Entretanto, o projeto burguês é transnacional, e o processo de globalização esgarça as fronteiras e constitui um campo de subjetividade social também transnacional e de interesse dos processos de reprodução das relações de produção do capital. Nesse caso são antiemancipatórios e ao mesmo tempo, em função da ideologia da modernidade, imprimem uma aura de atualidade e de impacto real que nos confunde. Tomamos essa forma global como a realidade por excelência e o territorial como tradicional, superado, dispensável, atrasado. No mesmo texto mencionado, Ciampa faz uma brincadeira com o termo metamorfose: "Obviamente, estou falando da metamorfose humana (e não da borboleta ou da pipoca)." (p. 3) Ele confere um estatuto diferenciado ao humano da coisa em si. Entretanto, o que se entende por mudança no mundo globalizado da forma como foi exposta é a pura coisificação (como forma reificada) tomada como signo da modernidade. É dessa forma que está constituída a construção da identidade coletiva.

Agora podemos concluir evocando a discussão inicial sobre a globalização. Toda a discussão sobre a globalização sofre de um viés economicista e está pautada pelo capital financeiro e industrial. Trata-se da livre circulação do capital volátil, favorecido pelo avanço da tecnologia de informação e pelas opera- ções on-line e trata-se também da busca de mão de obra barata para garantir a produção de baixo custo de produtos que são distribuídos em todo o planeta. Entretanto, quando falamos desse processo, falamos de 20,30, no máximo 40 países em todo o planeta em que há investimento de capital financeiro volátil e que são, também, industrializados. E o restante do planeta? Não faz parte da globalização? Que globalização é essa que não é global?

A realidade é que o capital desconsidera aquilo e aqueles que não reproduzem o capital. Essa lógica imperativa do capitalismo continua valendo como nunca. Somente quando há risco físico - essa é a grande novidade do período inaugurado com o 11 de setem$\underline{\text { bro }}$ - essas regiões e essa gente passam a interessar de alguma forma, como ocorreu com o ataque americano ao Afeganistão.

E aqui está o desafio para as Ciências Humanas e Sociais e, no nosso caso, o desafio para a Psicologia Social: a construção de respostas para esse mundo em rede, para a construção de novos campos de subjetividade que hoje passam pela condição regional, pela sociedade em rede, pelo fenômeno da globalização.

Para nós, latino-americanos, esse é um desafio peculiar, já que representamos polo de interesse do capital global e somos diuturnamente atacados pela voracidade desse modelo. Alguns países mais, como é o caso do México, Brasil, Argentina e Chile. Outros menos, por enquanto. Qual é o nosso desafio: discutirmos nosso campo de identidade. Hoje, como nunca, o problema da identidade está posto. A idade média e o renascimento não colocavam a questão da identidade no centro dos seus interesses. Talvez essa questão tenha somente interessado profundamente aos gregos clássicos, como apontam Vernant e Vidal-Naquet (1977) no texto já citado. Os descobrimentos e o novo mundo e culturas descobertas colocam novamente a pergunta para os europeus - afinal, quem eu sou? A resposta veio na psicologia sob a forma racista da teoria do caráter. Eu sei quem sou, eu sou o melhor! E, do ponto de vista econômico e político, tivemos a constituição do nacionalismo, exacerbado pelo nazifascismo. As teorias sobre o caráter e a superioridade das raças foram superadas particularmente a partir dos trabalhos dos antropólogos da escola de Chicago, durante as décadas de 30 e 40. Já a discussão sobre identidade nacional, pela possível ligação com o tema do nacionalismo, ficou relegada a um segundo plano. Está no momento de recuperarmos esse debate a partir das novas condições: nova ordem mundial, impossibilidade da constituição de um estado nacional nos moldes do estado-nação mencionados por Hardt e Negri (2001), constituição das redes a partir dos territórios, redefinições culturais a partir do próprio território. 
Para tanto, é fundamental uma psicologia social que responda aos problemas gerais e aos específicos. Que responda a nossa demanda de como são formadas as dimensões subjetivas da realidade influenciadas pela dinâmica da mundialização e, ao mesmo tempo, nossa demanda regional e a manutenção (culturalmente negociada) das dimensões subjetivas tradicionais. É claro que não haverá teoria que sozinha produza todas essas respostas, mesmo porque não teremos mais a construção de sistemas como no início do século XX. Cabe a nós a produção de uma pauta de intervenção, de uma pauta que aponte para o estudo da construção da subjetividade do ponto de vista regional, que considere nossas bases culturais de produção de subjetividade, nossos meios peculiares de produzir sociabilidade e ao mesmo tempo as formas de generalizar esse conhecimento, de garantir seu caráter genérico. São maneiras de entender o psiquismo nestes novos tempos e, ao mesmo tempo, formas de quebrar a hegemonia da compreensão do psiquismo humano a partir da experiência europeia e americana. Para tanto, precisamos dar o primeiro passo com decisão e coragem: conhecendo-nos, vamos poder dialogar com a psicologia social de todo o mundo, da chinesa à psicologia de Kosovo, da Nova Guiné à Índia, dos EUA à psicologia Russa. Vamos construir uma psicologia social que saiba compreender nossos problemas regionais e nossa condição humana genérica. Quem sabe, não estaremos também ajudando a construir um novo mundo, para além da condição que aponta o futuro que estão nos delineando?

\section{Notas}

1 Este trabalho é fruto do período passado na UnB/IP/PST através de bolsa pesquisador visitante CNPq (fev. 2004 a fev. 2005) e como professor visitante (2005-2006). O trabalho foi parcialmente apresentado no VII Congreso al Encuentro de la Psicología Mexicana (Acapulco) em 2004, e o texto dessa fala foi publicado em 2006 na revista da AMAPSI - México com o título "Globalización y Territorio". O presente trabalho é o texto final, ampliado e melhorado a partir do trabalho realizado nesses anos de UnB e no Programa de Estudos Pós-Graduados em Psicologia Social da PUC-SP.

2 Recentemente presenciamos uma disputa entre o Brasil e o Uruguai em relação ao Mercosul. O governo Tabaré Vázquez, considerado um governo de esquerda, se interpôs aos interesses brasileiros de liderar a América do Sul realizando acordo econômico diretamente com os Estados Unidos. Intensas negociações do governo Lula e de Tabaré Vázquez, com promessas de vantagens para o Uruguai, minimizaram o episódio, que poderia trazer prejuízos políticos para a organização do Mercosul. O que chama a atenção é a utilização da mediação americana como gendarme da política mundial na relação entre governos supostamente antineoliberais.

3 Há certa inspiração na teoria da Ação Comunicativa de Habermas (1999) e sua proposta da mudança do paradigma da produção.
4 Em 2008 e 2009 a crise gerada pelo sub-prime no mercado financeiro americano e que atinge todo o sistema financeiro mundial fornece uma atualidade impressionante às palavras de Walllerstein e de Perry Anderson.

5 Não cabe aqui uma discussão mais profunda, de caráter antropológico, sobre a identidade latino-americana, mas acompanhamos Darcy Ribeiro (1992) em sua análise e apontamos como referência o seguinte trecho: "En las Américas, exceptuando las altas civilizaciones indígenas y el caso del Paraguay, aislado de contactos por su temprano encierro, a los que Europa no consiguió asimilar de una manera concluyente, el resto resultó moldeado por completo de acuerdo con el patrón lingüístico y cultural europeu. El español, el portugués y también el inglés hablados en las Américas, son mucho más homogéneos e indiferenciados que los idiomas de la Península Ibérica y de las Isla Británicas. Esta uniformidad lingüística, cultural y también étnica, sólo es explicable como resultado de un proceso civilizatorio mucho más intenso y poderoso, capaz por ello de fundir los contingentes más dispares en la constitución de nuevas variantes de las etnias civilizadoras." (p. 67).

6 Tomamos conhecimento da pesquisa realizada por Lynn A. Meisch (2002) com o povo Otavalo nos Andes equatorianos. Meisch conviveu com esse grupo por um bom período e relata a maneira como eles preservam sua cultura e costumes e ao mesmo tempo sua incrível disponibilidade para adquirir novos conhecimentos, entre eles as novas tecnologias de informação. Chama atenção, particularmente, a estrutura de compadrio estabelecida no grupo e forma importante de sociabilidade. O próprio autor ganhou alguns afilhados durante sua estadia no povoado, ganhou presentes, emprestou dinheiro, recebeu de volta e emprestou mais algum. A pesquisa desse antropólogo corrobora a posição aqui assumida na análise dos moradores de Caspana.

7 Há disponível na internet site de Ana van Meegen Silva, com a íntegra do mestrado da autora, que realizou pesquisa participante junto aos habitantes desse quilombo em 1999. Muito importante também é o trabalho da professora Mari Nazaré Baiocchi, que publicou Kalunga, Povo da Terra. Brasília: Ministério da Justiça, 1999.

8 Silva registra o batismo de crianças por um culto à lua; entretanto ele está caindo em desuso, e os moradores do quilombo não guardam na memória qualquer referência desse culto, se de origem indígena ou de origem africana. Não há ainda nenhum estudo antropológico que identifique relação com cultos existentes ou identificados entre os afrodecendentes ou das populações indígenas do Brasil.

9 Em julho de 2006, no Seminário Nacional A questão da terra, desafios para a psicologia, promovido pelo Conselho Federal de Psicologia, uma liderança Kalunga falou sobre o choque representado pelo que ele considerava a invasão evangélica no quilombo. Esse fator de mudança religiosa incomodava muito os habitantes mais velhos que seguiam a tradição católica mencionada neste artigo. Um dos problemas é que a tradição católica estava perfeitamente consoante com as festas, cantos e danças tradicionais e oriundas da cultura africana. As festas, por sua vez, incluíam o consumo da aguardente produzida no próprio quilombo. A concepção evangélica, implantada na região, trouxe a proibição dessas expressões culturais e conquistou adeptos entre os mais jovens.

10 Apesar de não considerar o termo "comunidade" apropriado, não há outro termo para designar o quilombo Kalunga, do 
ponto de vista sociogeográfico. Usamos como referência o texto básico de macrossociologia organizado pelo professor Florestan Fernandes (1975), Comunidade e Sociedade no Brasil, particularmente o capítulo dedicado à pequena comunidade.

11 O excelente trabalho de Ana Mercês Bahia Bock (1999), Aventuras do Barão de Münchhausen na Psicologia, traz uma minuciosa análise sobre as formas de naturalização do conhecimento nesse campo.

12 Ciampa, A. C. Identidade: um paradigma para a psicologia social? Texto apresentado em simpósio do $10^{\circ}$ Encontro Nacional da Associação Brasileira de Psicologia Social ABRAPSO (8 a 12/10/99).

\section{Referências}

Aderson, P. (2002, setembro-outubro). Force and Consent. New Left Review, 17, 5-30.

Baiocchi, M. N. (1999). Kalunga, Povo da Terra. Brasília: Ministério da Justiça.

Bock, A. M. B. (1999). Aventuras do Barão de Münchhausen na Psicologia. São Paulo: EDUC/CORTEZ.

Castro, R. V. \& Martinez, C. (1996). Poblaciones Indígenas de Atacama. In J. Hidalgo L. et al. (Orgs.), Culturas de Chile. Etnografia: sociedades indígenas contemporáneas y su ideología (Vol. 2, pp. 69-109). Santiago de Chile: Andrés Bello.

Fernandes, F. (1975). Comunidade e Sociedade no Brasil (2 ed.). São Paulo: Editora Nacional.

Fukuyama, F. (1992). O fim da história e o último homem. Rio de Janeiro: Rocco.

Furtado, O. (2008). As Dimensões subjetivas da realidade: uma discussão sobre a dicotomia entre a subjetividade e a objetividade no campo social. In O. Furtado \& R. González (Orgs.), Por uma epistemologia da subjetividade ( $2^{\mathrm{a}}$ ed., pp. 91-105). São Paulo: Casa do Psicólogo.

García Canclini, N. (2003). Culturas híbridas: estrategias para entrar y salir de la modernidad. México: Grijalbo.

Giddens, A. (2002). Modernidade e identidade. Rio de Janeiro: Jorge Zahar.

Hardt, M. \& Negri, A. (2001). Império (B. Vargas, Trad., $3^{\mathrm{a}}$ ed.). Rio de Janeiro: Record.

Hutton, W. \& Giddens, A. (Orgs.). (2004). No Limite da Racionalidade: convivendo com o capitalismo global (M. B. Medina, Trad.). Rio de Janeiro: Record.

Kahneman, D. \& Tversky, A. (2000). Choices, Values, and Frames. New York: Cambridge University Press and the Russell Sage Foundation.

Kuhn, Th. S. (1978). A Estruturas das Revoluções Cientificas ( $2^{\mathrm{a}}$ ed.). São Paulo: Perspectiva.
Lukács, G. (1981). Per l'ontologia dell'e essere sociale. Roma: Riuniti.

Meisch, L. A. (2002). Andean Entrepreneurs: Otavalo merchants \& musicians in the global arena. Austin: University of Texas Press.

Santos, M. (2002). O retorno do território. In M. Santos, M. A. A. Souza, \& M. L. Silveira (Orgs.), Território: globalização e fragmentação ( $5^{\mathrm{a}}$ ed., pp. 15-20). São Paulo: Annablume/Hucitec/ANPUR.

Ribeiro, D. (1992). Las Americas y la Civilización: processo de formación y causas del desarrollo desigual de los pueblos americanos. Caracas: Biblioteca Ayacucho.

Silva, A. van M. (1999). Kalunga:identidade étnica de uma comunidade remanescente de quilombos. Amesterdã: Vrije Universiteit. Acesso em 20 de outubro, 2007, em http:// geocities.yahoo.com.br/comunidade_kalunga

Vernant, J-P \& Vidal-Naquet, P. (1977). Mito e tragédia na Grécia Antiga. São Paulo: Duas Cidades.

Wallerstein, I. (1999, 17 de outubro). Entrevista concedida a Gustavo Opschpe [Caderno Mais!]. Folha de São Paulo, pp. 5-9.

Wallerstein, I. (2003a). Cancum: o colapso da ofensiva neoliberal. Acesso em 20 de outubro, 2007, em http://fbc. binghamton.edu/commentr.htm.

Wallerstein, I. (2003b, julho-agosto). Entering Global Anarchy. New Left Review, 22, 27-35.

Recebido em: 09/04/2009

Revisão em: 23/09/2009

Aceite final em: 12/03/2010

Odair Furtado possui doutorado em Psicologia (Social) pela PUC de São Paulo (1998). É professor da Faculdade de Psicologia e Programa de Estudos Pós-Graduados em

Psicologia Social da PUC-SP. Endereço: Rua Ministro Godói 969 - $4^{\circ}$ andar - Sala 4A-01, Perdizes. São Paulo/SP, Brasil. CEP 05015-000. Email: odairfurtado@pucsp.br

\section{Como citar:}

Furtado, O. (2010). Dialética e contradições da construção da identidade social. Psicologia \& Sociedade, 22(2), 259-268. 